\title{
Forecasting Further Costs of Fixed Assets in the Gas Transportation System for Management Purposes
}

\author{
Liliana Horal \\ Vice-rector on scientific and pedagogical \\ work \\ Ivano-Frankivsk National Technical \\ Univercity of Oil and Gas \\ Ivano-Frankivsk, Ukraine \\ liliana.goral@gmail.com; \\ https://orcid.org/0000-0001-6066-5619 \\ Larisa Galyuk \\ Accountig and taxation dept. \\ Ivano-Frankivsk National Technical \\ Univercity of Oil and Gas \\ Ivano-Frankivsk, Ukraine \\ barva7@ukr.net
}

\author{
Sofiia Kafka \\ Accountig and taxation dept. \\ Ivano-Frankivsk National Technical \\ Univercity of Oil and Gas \\ Ivano-Frankivsk, Ukraine \\ Kafka@i.ua; \\ http://orcid.org/0000-0002-6031-383X
}

\author{
Yuriy Chuchuk \\ Accountig and taxation dept. \\ Ivano-Frankivsk National Technical \\ Univercity of Oil and Gas \\ Ivano-Frankivsk, Ukraine \\ yuriy.chuchuk@gmail.com; \\ http://orcid.org/0000-0002-3155-7739
}

\begin{abstract}
One of the most important tasks of the sustainable development of the domestic gas industry is the maintenance of industrial capacities of the industry in working condition. The solution to this problem is complicated by the reduction of the financial base of the processes of renewal of fixed assets: the existing gas tariffs in the gas supply system do not allow to carry out repairs, reconstruction and modernization of gas networks in the necessary volumes, terms of use of separate parts and units which have already expired. As a result, this leads to a reduction in the industrial safety of gas transportation and the gas distribution system as a whole. At the same time, there are significant internal reserves for improving the efficiency of gas transport companies. One of these reserves is the optimization and reduction of maintenance costs, current, emergency and other types of repairs of fixed assets through the active introduction of digitalization of management processes and the creation of a single information space for the adoption of management decisions.
\end{abstract}

On the basis of the systematic approach, a comprehensive study has been carried out of the volumes and conditions of further costs of fixed assets in the system of gas transportation enterprises, the order of formation and presentation in these companies' financial statements of information on operations with repairs of fixed assets, restoration and maintenance of their working capacity. The research methods used include analysis and synthesis, generalization and abstraction, as well as special methods of cluster, discriminant and linear regression analysis to predict future costs.

As further costs of fixed assets in the natural gas transportation system grow by at least $10 \%$ each year, management of such processes requires reliable information both in the financial statements and for operational purposes. It has been established that the volume of repair works depends on the type of repair and complexity of the objects of the fixed assets that are being repaired. To calculate the estimated cost of repairs $(y)$ it is expedient to take into account the minimum period of use of fixed assets $\left(x_{1}\right)$, the actual number of years of their operation $\left(x_{2}\right)$, repair complexity of fixed assets of the corresponding group $\left(x_{3}\right)$ and the initial or revalued value of fixed assets $\left(x_{4}\right)$.

Forecasting of the magnitude and behavior of subsequent costs has been carried out in the following stages: clusterization of groups of fixed assets; groups, which should include observation (for this purpose the results of discriminant analysis are used) have been defined; the coefficients of the linear function (using discriminant and linear regression analysis) has been found; linear combinations of values $x_{1}, x_{2}$, $x_{3}, x_{4}$ with corresponding coefficients in the amount with a free member (obtained using linear regression analysis) gave a prognosis of the value of $y$.

The estimated implementation of the models has proved that the quantitative characteristics of this ratio are dependent on the physical deterioration and repair complexity of the objects of fixed assets. The proposed model is self-sufficient as a methodological tool for organizing accurate accounting of expenses for repair of fixed assets and the efficiency of using the resource potential of enterprises in the oil and gas industry. It is one of the most realistic and effective means of forecasting for the purpose of managing repair work in the system of natural gas transportation.

Keywords-further expenses, repair, forecasting, fixed assets, enterprises of gas transportation

\section{INTRODUCTION}

One of the most important tasks of the sustainable development of the domestic gas industry is the maintenance of industrial capacities of the industry in working condition. The solution to this problem is complicated by the reduction of the financial base of the processes of fixed assets renewal: existing tariffs on gas supply system do not enable us to carry out repairs, reconstruction and modernization of gas networks in the necessary volumes, the term of the use of separate parts and units has already expired. As a result, this reduces the industrial safety of the gas distribution system as a whole. 
At the same time, there are significant internal reserves for improving the efficiency of gas transport companies. One such reserve is the optimization and reduction of maintenance costs, running, emergency and other types of fixed assets repairs by improving the system of internal control, creating a single information space for the adoption of management decisions.

An important problem for the enterprises of the oil and gas industry is the excessive period of operation of the fixed assets. The unsatisfactory state of the pipelines leads to their depressurization and is accompanied by the spillage and the entry of petroleum products into the soil, contamination of surface and groundwater, which causes significant costs both for the repair of fixed assets and for the restoration of the environment. The peculiarities of operating conditions of non-current assets of the oil and gas industry are characterized by extreme aggressiveness of the environment, physical deterioration and excessive exploitation of technological facilities of main gas pipelines and causes significant further expenses for their repair and maintenance. The processes of reproduction of fixed assets at gasdistributing enterprises are slow, and the further costs for their repair and operation tend to increase.

\section{RESEARCH ANALYSIS AND PROBLEM STATEMENT}

The questions of the theory, organization and management of further expenses for repairs and modernization of fixed assets were considered in their works by domestic and foreign scientists, in particular: M. Bondar [1], A. Gorener [2], A., N. Khorunzhak [3], E. Kryzhanivskyi [4], S. Legenchuk [5], O Palyvoda and V. Plavan [6], V. Vovk [7], Z.- M. Zadorozhnyi [8], I. Zapuhlyak [9], O. Zhukovska and L. Fynzilberg [10]. Yet there is a number of unexplored problems, in terms of using methods for forecasting the amount and behavior of future costs for repairs and modernization of fixed assets that require attention, more thorough analysis and resolution. The problematic aspects of the subject under study include the development of models for the development of a controlled object and the justification of the forecast indicators (numerical characteristics, volumes and terms of work) in connection with their likely nature, the direction of management decisions regarding the received parameters of forecasting.

\section{THE PURPose OF THE ARTICLE}

The purpose of the article is to obtain scientifically substantiated variants of trends in the development (change) of further costs of fixed assets in the system of natural gas transportation (indicators of its condition and development) in time and space taking into account economic ties and regularities. The sources of information for forecasts are the data of financial statements and economic indicators of the state of Ukrtransgas JSC fixed assets for 2015-2017, obtained in the process of communication or open access. Methods of the analysis of series considering time and methods of the analysis of causal connections are applied in the article for forecasting.

\section{RESEARCH RESULTS}

In the system of gas transportation, the main causes of repair work are corrosion damages to gas complex facilities, and their share will continue to increase, because after 20 years of the metal operation the total number of failures of its work from corrosion increases up to $35 \%$. Therefore, in the control system it is necessary to provide effective methods for the formation of reliable information on the costs of fixed assets repairs.

This concerns, first of all, scientific and methodological substantiation and solving key tasks for carrying out repair works at the enterprises of the oil and gas industry taking into account the variety of fixed assets (from the systems of main gas pipelines, buildings up to aerial lines of electric power transmission), which requires high qualification of the executors, determination of operationally possible zones of reliable gas supply, optimization of gas flows distribution, level of technological reserves based on operational and reliable information.

Until now, in the repair works at the enterprises of the oil and gas industry, the share of mechanized labor remains fairly low at $30 \%$, the rest ones - are manually executed welding, the restoration of the designed depth of laying adjacent overhead crossing of the pipeline underground sections, the performance of work to prevent the formation of erosion, soil sedimentation and so on.

For the purpose of controlling the repair cost, it is necessary to determine the technical condition of fixed assets. At the enterprises of the oil and gas industry, as ordered by the highest management personnel, commissions are annually organized, which examine all objects and determine the repair program to be carried out in the reporting period. Thus, JSC Ukrtransgaz develops a repair program based on the main sections regarding types of fixed assets and in terms of the structural subdivisions of the enterprise that perform the specified works. Namely: Section 1. The linear part, including operation of main gas pipelines and gas distribution stations, protection against corrosion, repair of power equipment of the linear part of main gas pipelines and gas distribution stations, repair of gas measuring and metrology devices, safety equipment of gas mains linear part and gas distribution stations, buildings and constructions for the production purpose of the linear part;

Section 2. Gas Metering Stations (GMS), including repair of technological equipment and objects of GMS, power equipment of GMS, systems of automation of production and telemechanics GMS, safety devices of GMS, buildings and constructions of the production purpose of GMS;

Section 3. Compressor stations (CS), including repair of technological equipment $\mathrm{KC}$, anticorrosion protection, repair of power equipment of CS, systems of automation of production, means of gas measurement and metrology, buildings and constructions for the production purpose of CS;

Section 4. Underground gas storage facilities (UGSF), including anti-corrosion protection, system repair, automation of production, means of gas measurement and metrology, repair of buildings and structures for the production purpose of UGSF;

Section 5. Communication systems and information technologies, including repair of linear communication facilities (cable, relay lines), equipment of communication centers (telephone station, switching equipment), radio 
communication equipment (radio towers, base and subscriber stations);

Section 6. Other repair objects, c. including repair of auxiliary buildings and structures, administrative buildings, auxiliary facilities of power engineering, automation and telemechanics, auxiliary stationary equipment (machines and mechanical equipment), motor vehicles and special purpose machinery and other safety equipment.

When reviewing fixed assets, the commission uses a list of defects, which separately describe the repair work and time in hours spent on them. On the basis of the list of defects and the actual state of fixed assets, the commission makes summary report of the technical review of fixed assets. For each group of fixed assets facilities the time of the last repair is indicated in the list of defects, as well as the type of repair works and their scape, which must be performed in subsequent periods.

The scope of repair works depends on the type of repair and complexity of the objects of non-current assets that are being repaired. The latter is determined by the number of parts from which the object of repair is composed, its main dimensions, the necessary accuracy of processing, etc. In accordance with the complexity of repair and its laborintensity, all fixed assets in the enterprise can be divided into groups of repair complexity.

In the repair system at the enterprises of the oil and gas industry, the average standards of labor-intensive repair operations in hours per unit of repair complexity by the type of repair work (for example, welding, machine tools) are approved.

To calculate the projected repair cost (y), account must be taken of the minimum period of fixed assets use, the actual number of years of their operation, repair complexity of fixed assets of the respective group and the initial estimation or revaluation of fixed assets:

$$
y=f\left(x_{1}, x_{2}, x_{3}, x_{4}\right)
$$

where,

$\mathrm{y}$ is expenses for repair of fixed assets; $\mathrm{UAH}$

$x_{1}$ is the initial estimation or revaluation of fixed assets,

$x_{2}$ is the minimum period of using fixed assets, years;

$x_{3}$ is number of years of fixed assets operation, years;

$x_{4}$ is repair complexity, units.

Model of costs calculation on repair of fixed assets (1) gives the recommended value of subsequent costs of fixed assets for the corresponding forecast period. Based on the indicators $x_{1}, x_{2}, x_{3}, x_{4}$, we conduct the clustering of observations. A hierarchical method of cluster analysis is depicted on a dendrogram (Fig. 1).

As can be seen from the resulting drawing, the whole set of observations can be divided into two main groups. Relatively small numbers of observations do not fall into these groups. We will treat them as special and exclude them from consideration.

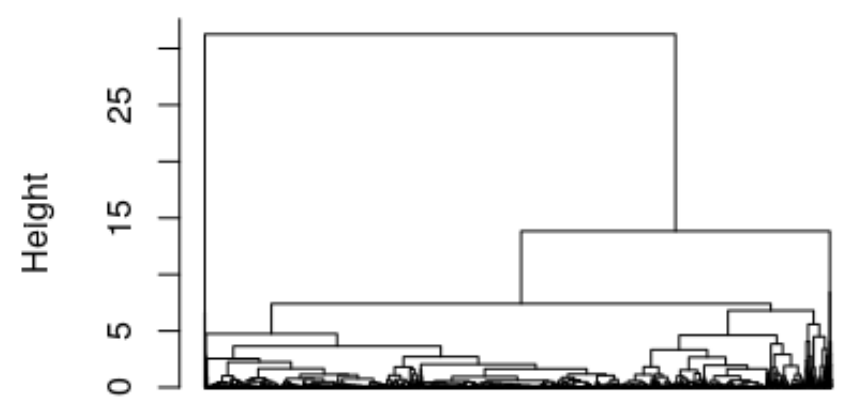

Fig. 1. Dendrogram of observation clustering indicators $x_{1}, x_{2}, x_{3}, x_{4}$ for 2015-2017 years.

Emphasizing alternating groups 2, 3, 4, 5, 6, 7, 8, we can see that starting from the division into 6 groups, the composition of the first two is stabilized (see Tables 1-8).

TABLE I. The Results OF The Allocation Of Two Groups By THE NUMBER OF OBSERVATIONS FOR 2015-2017 YEARS

\begin{tabular}{|c|c|c|}
\hline Number of groups & $\mathbf{1}$ & $\mathbf{2}$ \\
\hline Number of observations & 3283 & 3 \\
\hline
\end{tabular}

TABLE II. THE RESULTS OF THE ALLOCATION OF THREE GROUPS BY THE NUMBER OF OBSERVATIONS FOR 2015-2017 YEARS

\begin{tabular}{|c|c|c|c|}
\hline Number of groups & $\mathbf{1}$ & $\mathbf{2}$ & $\mathbf{3}$ \\
\hline Number of observations & 3270 & 3 & 13 \\
\hline
\end{tabular}

TABLE III. THE RESULTS OF THE ALLOCATION OF FOUR GROUPS BY THE NUMBER OF OBSERVATIONS FOR 2015-2017 YEARS

\begin{tabular}{|c|c|c|c|c|}
\hline Number of groups & $\mathbf{1}$ & $\mathbf{2}$ & $\mathbf{3}$ & $\mathbf{4}$ \\
\hline Number of observations & 3270 & 3 & 1 & 12 \\
\hline
\end{tabular}

TABLE IV. The Results OF Determination OF Five Groups By QUANTITY OF OBJECTIVES FOR 2015-2017 YEARS

\begin{tabular}{|c|c|c|c|c|c|}
\hline Number of groups & $\mathbf{1}$ & $\mathbf{2}$ & $\mathbf{3}$ & $\mathbf{4}$ & $\mathbf{5}$ \\
\hline Number of observations & 1089 & 2181 & 3 & 1 & 12 \\
\hline
\end{tabular}

TABLE V. The Results Of SElEction Of The SiXth Groups By QUANTITY OF OBJECTIVES FOR 2015-2017 YEARS

\begin{tabular}{|c|c|c|c|c|c|c|}
\hline Number of groups & $\mathbf{1}$ & $\mathbf{2}$ & $\mathbf{3}$ & $\mathbf{4}$ & $\mathbf{5}$ & $\mathbf{6}$ \\
\hline Number of observations & 964 & 2181 & 3 & 1 & 125 & 12 \\
\hline
\end{tabular}

TABLE VI. The Results Of SELECTION OF SEPARATE Groups By QUANTITY OF OBJECTIVES FOR 2015-2017 YEARS

\begin{tabular}{|c|c|c|c|c|c|c|c|}
\hline Number of groups & $\mathbf{1}$ & $\mathbf{2}$ & $\mathbf{3}$ & $\mathbf{4}$ & $\mathbf{5}$ & $\mathbf{6}$ & $\mathbf{7}$ \\
\hline Number of observations & 964 & 2181 & 1 & 1 & 125 & 12 & 2 \\
\hline
\end{tabular}

TABLE VII. THE RESULTS OF DETERMINATION BY ALL GROUPS BY QUANTITY OF OBJECTIVES FOR 2015-2017 YEARS.

\begin{tabular}{|c|c|c|c|c|c|c|c|c|}
\hline Number of groups & $\mathbf{1}$ & $\mathbf{2}$ & $\mathbf{3}$ & $\mathbf{4}$ & $\mathbf{5}$ & $\mathbf{6}$ & $\mathbf{7}$ & $\mathbf{8}$ \\
\hline Number of observations & 964 & 2181 & 1 & 1 & 34 & 12 & 2 & 91 \\
\hline
\end{tabular}


For further research, we select the observation from these two groups (we denote them through $G_{1}$ and $G_{2}$ ).

Separate samples over the years.

2015 year.

From the next dendrogram, we conclude that there are two large groups of observations.

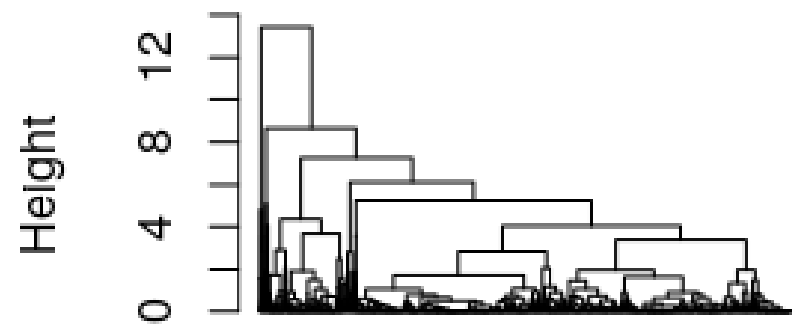

Fig. 2. Dendrogram of clustering observations of indicators $x_{1}, x_{2}, x_{3}, x_{4}$ by 2015 year

The division into groups is shown in table 8 .

TABLE VIII. ReSUlts OF QUANTITY OF OVERVIEW By 2015 YeAR

\begin{tabular}{|c|c|c|c|c|}
\hline Number of groups & $\mathbf{1}$ & $\mathbf{2}$ & $\mathbf{3}$ & $\mathbf{4}$ \\
\hline Number of observations & 369 & 101 & 7 & 3 \\
\hline
\end{tabular}

As in the general case, these are groups 1 and 2.

2016 year.

From the next dendrogram, we conclude that there are two large groups of observations.

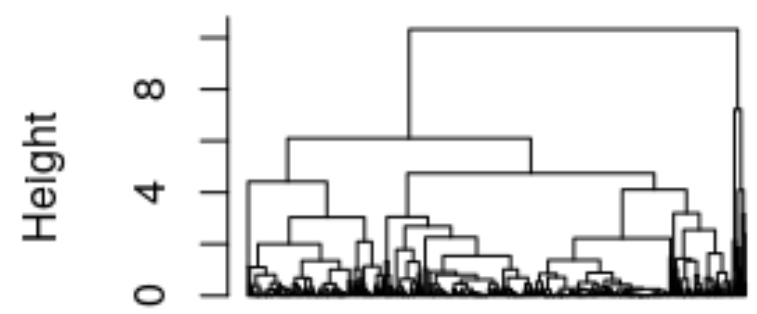

Fig. 3. Dendrogram of clustering observations of $x_{1}, x_{2}, x_{3}, x_{4}$ by 2016 year

The division into groups in 2016 is shown in table 9 .

TABLE IX. RESUlts OF QuANTITY OF OBSERVATIONS For 2016 YEAR

\begin{tabular}{|c|c|c|c|c|}
\hline Number of groups & $\mathbf{1}$ & $\mathbf{2}$ & $\mathbf{3}$ & $\mathbf{4}$ \\
\hline Number of observations & 426 & 12 & 168 & 5 \\
\hline
\end{tabular}

As in the general case, it is two groups, but 1 and 3 . We will call them (as before) $G_{1}$ and $G_{2}$.

\section{7 year}

From the next dendrogram, we conclude that there are two large groups of observations. Although there are some special and not very small groups of observations.

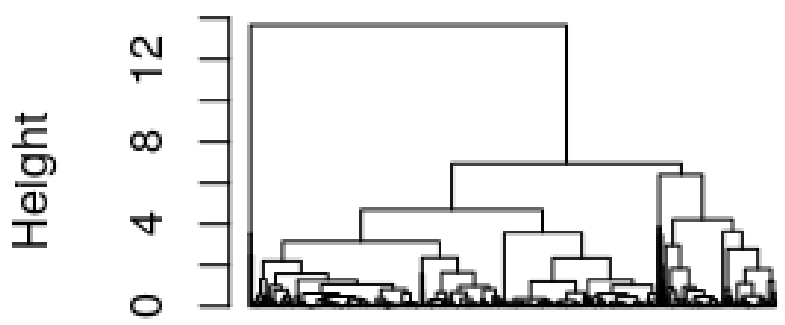

Fig. 4. Dendrogram of observation clustering indicators $x_{1}, x_{2}, x_{3}, x_{4}$ for 2017 year

The division into groups in 2017 is given in table 10 .

TABLE X. Results OF THE QuANTITy OF OBSERVATIONS For 2017 YEAR

\begin{tabular}{|c|c|c|c|c|c|c|}
\hline Number of groups & $\mathbf{1}$ & $\mathbf{2}$ & $\mathbf{3}$ & $\mathbf{4}$ & $\mathbf{5}$ & $\mathbf{6}$ \\
\hline Number of observations & 320 & 1792 & 6 & 20 & 38 & 19 \\
\hline
\end{tabular}

As in the general case, large groups are groups 1 and 2 .

Discriminant analysis.

The next step is to apply a linear discriminant analysis in order to find the rule by which observation should be attributed to one or another of the selected groups. To construct a discriminant function we divide the entire sample into two parts (teaching and test). The average values of the characteristics $x_{1}, x_{2}, x_{3}, x_{4}$ in the groups $G_{1}$ and $G_{2}$ in the working sample are given in the following table 11.

TABLE XI. MEDIUM SizES CHARACTERISTICS $X_{1}, X_{2}, X_{3}, X_{4}$ IN GROUPS $G_{1}$ I $G_{2}$ FOR 2015-2017 YEARS

\begin{tabular}{|l|c|c|c|c|}
\hline Indexes & $\boldsymbol{x}_{\mathbf{1}}$ & $\boldsymbol{x}_{\mathbf{2}}$ & $\boldsymbol{x}_{\mathbf{3}}$ & $\boldsymbol{x}_{\mathbf{4}}$ \\
\hline$G_{1}$ & 4330067 & 395.37441 & 375.15640 & 81.77567 \\
\hline$G_{2}$ & 3997384 & 89.39429 & 71.58595 & 54.97147 \\
\hline
\end{tabular}

The coefficients of the linear discriminant function are given in table 12 .

TABLE XII. COEFFICIENTS OF THE LINEAR DISCRIMINATION FUNCTION FOR YEAR 2015-2017 YEARS

\begin{tabular}{|l|c|}
\hline \multicolumn{1}{|c|}{ Factors } & Value \\
\hline$x_{1}$ & $-6.098065 \mathrm{e}-10$ \\
\hline$x_{2}$ & $-3.996378 \mathrm{e}-03$ \\
\hline$x_{3}$ & $-9.027995 \mathrm{e}-03$ \\
\hline$x_{4}$ & $-6.112645 \mathrm{e}-03$ \\
\hline
\end{tabular}

If the scalar product of the vector of the coefficients of a linear discriminant function with a vector of deviations of the values of $x_{1}, x_{2}, x_{3}, x_{4}$ of the observed observation from the center (medium of mean vector) of one of the groups will be less than that of the center of another group, then this observation should be attributed to the first group.

When checking this procedure on the test portion of this sample, make sure it's fairly good resolution. Namely, in table 13 the results of the test for entering into their group of test observations are given. 
TABLE XIII. THE RESULTS OF VERIFICATION IN THEIR GROUP OF TESTIMONIAL OBSERVATIONS

\begin{tabular}{|l|l|c|c|}
\hline \multicolumn{2}{|c|}{ Indexes } & \multicolumn{2}{c|}{ Predictable } \\
\cline { 3 - 4 } \multicolumn{2}{|c|}{} & $\boldsymbol{G}_{\mathbf{1}}$ & $\boldsymbol{G}_{\mathbf{2}}$ \\
\hline \multirow{2}{*}{ Actual } & $G_{1}$ & 330 & 1 \\
\cline { 2 - 4 } & $G_{2}$ & 23 & 791 \\
\hline
\end{tabular}

As can be seen from the table, we have $99.7 \%$ of the correct results of the classifications of observations from group $G_{1}$ and $97.2 \%$ of group $G_{2}$.

Separate samples over the years.

The coefficients of the linear discriminant function are given in table 14

TABLE XIV. COEFFICIENTS OF THE LINEAR DISCRIMINATION FUNCTION FOR YEAR 2015-2017 YEARS

\begin{tabular}{|l|c|c|c|}
\hline \multirow{2}{*}{ Indexes } & \multicolumn{3}{|c|}{ Years } \\
\cline { 2 - 4 } & $\mathbf{2 0 1 5}$ & $\mathbf{2 0 1 6}$ & $\mathbf{2 0 1 7}$ \\
\hline$x_{1}$ & -0.00000000023 & -0.0000000185345 & -0.00000002475805 \\
\hline$x_{2}$ & -0.00397008086 & -0.0012838231587 & -0.01633272494322 \\
\hline$x_{3}$ & 0.016181704912 & 0.01005390451192 & 0.004716126672888 \\
\hline$x_{4}$ & -0.01640902602 & 0.01172219474606 & 0.008753083554826 \\
\hline
\end{tabular}

The average values of the characteristics $x_{1}, x_{2}, x_{3}, x_{4}$ in the groups $G_{1}$ and $G_{2}$ in the working sample are given in table 15 .

TABLE XV. The Middle Evaluation Of Characteristics $X_{1}, X_{2}$ $\mathrm{X}_{3}, X_{4}$ In Groups $G_{1}$ AND $G_{2}$ IN THE Working CHOICE For 2015-2017 YEARS

\begin{tabular}{|l|c|c|c|c|c|}
\hline Indexes & Years & $x_{1}$ & $x_{2}$ & $x_{3}$ & $x_{4}$ \\
\hline \multirow{3}{*}{$G_{1}$} & 2015 & 12230565.0 & 144.648648 & 127.010810 & 71.87027027 \\
\cline { 2 - 6 } & 2016 & 5165686.35 & 130.601941 & 122.941747 & 58.26699029 \\
\cline { 2 - 6 } & 2017 & 3509809.24 & 448.647398 & 416.393063 & 55.84393064 \\
\hline \multirow{3}{*}{$G_{2}$} & 2015 & 13367545.5 & 439.200000 & 415.560000 & 60.16000000 \\
\cline { 2 - 6 } & 2016 & 3509809.39 & 449.934065 & 433.582417 & 116.0439560 \\
\cline { 2 - 6 } & 2017 & 1594231.051 & 114.6862967 & 95.80860702 & 60.96715742 \\
\hline
\end{tabular}

The average values of the characteristics $x_{1}, x_{2}, x_{3}, x_{4}$ in the groups $G_{1}$ and $G_{2}$ in the working sample are given in table 16.

TABLE XVI. RESULTS OF VERIFICATION OF ANALYSIS IN ITS TYPE OF TESTING OBSERVATIONS FOR 2015-2017 YEARS

\begin{tabular}{|l|l|l|c|c|}
\hline \multirow{2}{*}{ Indexes } & Years & \multirow{2}{*}{ Groups } & \multicolumn{2}{|c|}{ Predictable } \\
\cline { 3 - 5 } & & & $\boldsymbol{G}_{\mathbf{1}}$ & $\boldsymbol{G}_{\mathbf{2}}$ \\
\hline Actual & 2015 & $G_{1}$ & 184 & 0 \\
\cline { 3 - 5 } & & $G_{2}$ & 0 & 51 \\
\cline { 3 - 5 } & 2016 & $G_{1}$ & 201 & 19 \\
\cline { 3 - 5 } & & $G_{2}$ & 1 & 76 \\
\cline { 3 - 5 } & 2017 & $G_{1}$ & 147 & 0 \\
\cline { 3 - 5 } & & $G_{2}$ & 5 & 904 \\
\hline
\end{tabular}

We have $100 \%$ correct results of prediction of classifications by $2015,91.4 \%$ of the correct results of the classifications of observations from group $G_{1}$ and $98.7 \%$ of group $G_{2}$ in 2016 and $100 \%$ of the correct results of observations classifications from group $G_{1}$ and $99.4 \%$ from group $G_{2}$ in 2017

\section{Linear regression analysis.}

Using the least squares method, we estimate the parameters of linear regression of the value $Y$ on $x_{1}, x_{2}, x_{3}, x_{4}$. In group $G_{l}$ coefficients of linear regression are calculated in table 17 .

TABLE XVII. LINEAR REGION'S COEFFICIENTS IN GROUP $G_{l}$ FOR 20152017 YEARS

\begin{tabular}{|c|c|c|c|c|}
\hline Free member & $x_{1}$ & $x_{2}$ & $x_{3}$ & $x_{4}$ \\
\hline$-6.14308 \mathrm{e}+05$ & $4.5197 \mathrm{e}-02$ & $1.197734 \mathrm{e}+03$ & $4.504954 \mathrm{e}+02$ & $1.744568 \mathrm{e}+03$ \\
\hline
\end{tabular}

In this case, the determination coefficient is equal to 0.87 .

For group $G_{2}$ the results are as follows: coefficients of linear regression are given in table 18.

TABLE XVIII. LINEAR REGRESSION COEFFICIENTS IN GROUP $G_{2}$ FOR 2015-2017 YEARS

\begin{tabular}{|c|c|c|c|c|}
\hline Free member & $\boldsymbol{x}_{\mathbf{1}}$ & $\boldsymbol{x}_{\mathbf{2}}$ & $\boldsymbol{x}_{\mathbf{3}}$ & $\boldsymbol{x}_{\mathbf{4}}$ \\
\hline$-1.34419 \mathrm{e}+04$ & $1.8998 \mathrm{e}-02$ & $-1.6158 \mathrm{e}+03$ & $3.856539 \mathrm{e}+03$ & $1.394705 \mathrm{e}+03$ \\
\hline
\end{tabular}

Determination factor is 0.84

Separate samples over the years.

2015 year

In group $G_{l}$, the linear regression and determination coefficients separately calculated for the period under study are shown in table 19 .

TABLE XIX. LINEAR REGRESSION AND DETERMINATION COEFFICIENTS IN GROUP $G_{1}$ FOR THE RESEARCH PERIOD

\begin{tabular}{|c|c|c|c|c|c|}
\hline $\begin{array}{c}\text { Free } \\
\text { member }\end{array}$ & $x_{1}$ & $x_{2}$ & $x_{3}$ & $x_{4}$ & $\begin{array}{c}\text { Determination } \\
\text { coefficient }\end{array}$ \\
\hline \multicolumn{6}{|c|}{2015} \\
\hline 123110.94 & 0.0012 & -889.82 & 816.92 & -402.33 & 0.86 \\
\hline \multicolumn{7}{|c|}{2016} & 336.57 & 0.89 \\
\hline 49494.83 & 0.0061 & -352.85 & 489.27 & & \\
\hline \multicolumn{7}{|c|}{2017} & -2579.43 & 0.84 \\
\hline
\end{tabular}

In group $G_{2}$, the linear regression and determination coefficients separately calculated for the period under study are shown in table 20. 
TABLE XX. LINEAR REGRESSION AND DETERMINATION COEFFICIENTS IN GROUP $G_{2}$ FOR THE RESEARCH PERIOD

\begin{tabular}{|c|c|c|c|c|c|}
\hline $\begin{array}{c}\text { Free } \\
\text { member }\end{array}$ & $x_{1}$ & $\boldsymbol{x}_{2}$ & $\boldsymbol{x}_{\mathbf{3}}$ & $\boldsymbol{x}_{\mathbf{4}}$ & $\begin{array}{c}\text { Determination } \\
\text { coefficient }\end{array}$ \\
\hline \multicolumn{6}{|c|}{2015} \\
\hline-14692.98 & 0.00012 & 63.18 & -42.23 & 923.11 & 0.80 \\
\hline \multicolumn{7}{|c|}{2016} \\
\hline 325646.53 & 0.0074 & 4016.68 & -3983.39 & -2633.51 & 0.83 \\
\hline \multicolumn{7}{|c|}{2017} & -859.58 & 0.80 \\
\hline
\end{tabular}

Forecasting is done in two stages:

We determine the group to which observations should be included. To do this we use the results of discriminant analysis.

Discriminant and linear regression analysis is used to find the coefficients of the linear function.

The linear combination of the values $x_{1}, x_{2}, x_{3}, x_{4}$ with the corresponding coefficients in the sum of the free member (obtained by linear regression analysis) gives a prognostic value of $y$.

The mathematical and statistical justification of the hypothesis regarding the dependence of the costs of repairing fixed assets on these factors in DMP Prykarpattransgaz is provided in this article. The calculations showed that the cost of repairs in accordance with the conducted economic and mathematical analysis will have the following linear dependence:

$$
y=-614308.9+0.04 x_{1}+1197.73 x_{2}+450.49 x_{3}+1744.56 x_{4}
$$

This amount of expenses is appropriate to reflect even in the accounting system, when the company pre-creates a reserve of future costs for the repair of fixed assets with a subsequent write-off at the expense of this repair reserve.

\section{CONCLUSIONS}

Estimated implementation of models proved that the value of further costs of fixed assets of DMP Prykarpattransgaz JSC Ukrtransgas (1) directly proportional to the factors - the minimum period of use of fixed assets $\left(x_{1}\right)$, the actual number of years of their operation $\left(x_{2}\right)$, repair complexity of fixed assets of the corresponding group $\left(x_{3}\right)$ and the initial or revalued value of fixed assets $\left(x_{4}\right)$. The quantitative characteristic of this ratio is dependent on the schematic structure, physical depreciation and real conditions of fixed assets operation. The self-contained model as a methodical tool for management of further expenses for the repair of fixed assets and the efficiency of using the resource potential of enterprises in the oil and gas industry is proposed. It is one of the most realistic, relatively low-cost and efficient means of estimating, forecasting and improving the efficiency of repair works in the system of main gas pipelines, and its application will facilitate the timely receipt and analysis of the necessary information by management, which will accelerate the adjustment of management decisions, if necessary.

\section{REFERENCES}

[1] Bondar, M., and N. Yershova. "Strategic Administrative Accounting In The Concept Of Values." In Proceedings III International Scientific and Practical Conference "Improvement of Accounting, Control, Audit, Analysis and Taxation in the Modern Conditions of Integration Processes in the World Economy, April 2018, pp. 173176. [Online]. Available: https://dspace.uzhnu.edu.ua/jspui/bitstream/lib/19079/1/\%D0\%91\%D 0\%BE\%D0\%BD\%D0\%B4\%D0\%B0\%D1\%80\%20\%D0\%9C.\%D0\% 86..PDF. Accessed on: 19 July 2019

[2] Gorener, A., K. Toker, and K. Ulucay. "Application of combined SWOT and AHP: A case study for a manufacturing firm", Procedia social and behavioral Sciences, vol. 58, pp. 1525-1534, 2012.

[3] Khorunzhak, N., O. Adamyk, and B. Adamyk. "Auditing of the Software of Computer Accounting System." CEUR-WS, 2018. [Online]. Available: http://dspace.tneu.edu.ua/jspui/bitstream/316497/ 31308/1/Adamyk paper 181.pdf. Accessed on: 19 July 2019

[4] Kryzhanivskyi, E., R. Hrabovskyi, and O. Mandryk. "Estimation of the serviceability of oil and gas pipelines after long-term operation according to the parameters of their defectiveness", Materials Science vol. 49, no. 1 (July/August 2013). DOI: 10.1007/s11003-013-9590-6.

[5] Legenchuk, S., and O. Usatenko. "Analysis of management forms of collective investment institutions to organise the accounting system." Economic Annals-XXI, no. 156(1-2), pp. 112-115, April 2016. DOI: 10.21003/ea.V156-0026.

[6] Palyvoda, O., and V. Plavan. "Assessment of synergies in forming of cluster organizational structures." Economic Annals-XXI 158, no. 342 (June/July 2016), 48-51. Vovk, V. Mathematical methods of operations research in economics and production systems. Lviv: Publishing Center of Ivan Franko National University of LNU, 2006.

[7] Zadorozhnyi, Z. M., B. Andrushkiv, O. Amosha, and S. Aptekar. Structural economic reforms: world experience, institutes, strategies for Ukraine. Ternopil: Economic Thought TNEU, 2018.

[8] Zapuhlyak, I. "Institutional framework for the development of domestic gas transportation enterprises." Economic Annals-XXI, no. 158, pp. 39-42, June/July 2016.

[9] Zhukovska, O., and L. Fynzilberg. Mathematical models of collective decision making. Kiiv: Osvita Ukrainy, 2018. 